\title{
The Reaction of Hydrazine with Cinnamic Acid Derivatives
}

\author{
W. O. GODTFREDSEN and S. VANGEDAL
}

Leo Pharmaceutical Products, Copenhagen, Denmark

\begin{abstract}
The product formed by reaction of ethyl einnemate with one mole equivalent of hydrazine hydrate is shown to be 3-phenyl-5-pyrazolidone and not as previously assumed cinnemic acid hydrazide.

Of the two products, formed upon treatment of ethyl $m$-nitrocinnamate with hydrazine hydrate, the main product $\left(m\right.$. p. $\left.139^{\circ}\right)$ is shown to be 3-(m-nitrophenyl)-5-pyrazolidone, while the by-product (m. p. $198^{\circ}$ ) is m-nitrocinnamic acid hydrazide.

The two pyrazolidones mentioned are able to condense with benzaldehyde forming benzylidene compounds to which betain formulas are proposed.

A method of synthesis of $\alpha, \beta$-olefinic acid hydrazides is given, consisting in treatment of the mixed anhydride of the appropriate $\alpha, \beta$ olefinic acid and monoethylcarbonic acid with hydrazine hydrate. By this method cinnamic acid hydrazide, $m$-nitrocinnamic acid hydrazide and $p$-nitrocinnamic acid hydrazide have boen synthesized.

Finally it is shown, that treatment of ethyl cinnamate with two mole equivalents of hydrazine hydrate leads to the formation of $\beta$-hydrazinodihydrocinnamic acid hydrazide.
\end{abstract}

The literature dealing with the reaction of the esters of $\alpha, \beta$-olefinic acids with hydrazine reveals that some confusion prevails with regard to this subject.

When treating ethyl cinnamate with hydrazine hydrate, Muckermann ${ }^{1}$ obtained a substance with m.p. $101^{\circ}$, which he assumed to be cinnamic acid hydrazide. This substance has the characteristic properties of a primary hydrazide, with the exception that it does not, as was to be expected, form cinnamoyl azide with nitrous acid, but 2-nitroso-3-phenyl-5-pyrazolidone. This reaction Muckermann explained to be due to cyclization upon treatment with nitrous acid. According to the same author, ethyl crotonate reacts similarly.

Upon treatment of ethyl $m$-nitrocinnamate with hydrazine hydrate, Curtius and Bleicher ${ }^{2}$ were able to isolate two isomeric compounds; both were assumed to be $m$-nitrocinnamic acid hydrazides. The main product (m. p. $139^{\circ}$ ) formed a nitrosopyrazolidone with nitrous acid, while the by-product (m. p. $198^{\circ}$ ) reacted normally, forming $m$-nitrocinnamic acid azide (Curtius 
and Kengott ${ }^{3}$ ). To both substances, however, the hydrazide structure was assigned, on the ground that they condensed with aldehydes and ketones.

Gansser and Rumpf 4 treated methyl $p$-nitrocinnamate with hydrazine hydrate and obtained as the main product $\beta$-( $p$-nitrophenyl)- $\beta$-hydrazinopropionic acid hydrazide and, in addition, minute quantities of a substance which was presumed to be $p$-nitrocinnamic acid hydrazide.

By causing ethyl metacrylate to react with anhydrous hydrazine, Lieser and Kemner ${ }^{5}$ obtained a substance which was assumed to be 4-methyl-5pyrazolidone, because it formed 2-nitroso-4-methyl-5-pyrazolidone with nitrous acid.

By reaction of $p$-phenylenediacrylic acid diethyl ester with hydrazine hydrate in alcohol Ruggli and Theilheimer ${ }^{6}$ obtained a substance which, upon treatment with nitrous acid, did not give the expected azide, but the nitrosopyrazolidone (c). The authors discuss whether the substance has the strueture (a) or (b), but they favour formula (a).

(a)

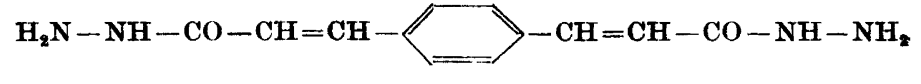

(b)<smiles>O=C1CC(c2ccc(C3CC(=O)NN3)cc2)NN1</smiles>

(c)<smiles></smiles>

Freri ${ }^{7}$ has synthesized the dihydrazides of itaconic acid, mesaconic acid, and citraconic acid from the corresponding methyl esters by reaction with hydrazine hydrate in alcohol. With nitrous acid all these hydrazides form azides in the normal manner. According to Curtius ${ }^{8}$, diethyl fumarate behaves similarly.

In an investigation into the reaction of hydrazine hydrate with lactones, Darapsky ${ }^{\theta}$ brought the unsaturated lactone, coumarin, to react with hydrazine hydrate in alcohol. He did not obtain $o$-coumaric acid hydrazide, but $\beta$-hydrazino-o-dihydrocoumaric acid hydrazide which, upon treatment with nitrous acid, formed 2-nitroso-3-(o-hydroxyphenyl)-5-pyrazolidone.

A similar observation has been made by Stodola 10 who, in an attempt to synthesize $\alpha$-benzoylaminocinnamic acid hydrazide from the corresponding methyl ester by reaction with hydrazine hydrate in methanol, obtained $\alpha$ benzoylamino- $\beta$-hydrazinodihydrocinnamic acid hydrazide which, upon heating in vacuo, split off hydrazine with the formation of 3-phenyl-4-benzoylamino-5-pyrazolidone. The structure of this compound was established from the ultraviolet absorption spectrum and the reaction with nitrous acid, whereby 2-nitroso-3-phenyl-4-benzoylamino-5-pyrazolidone is formed.

We have chosen cinnamic acid as the object of our investigation since it is one of the simplest and most thoroughly investigated representatives of $\alpha, \beta$-olefinic acids. 
It has been possibie to show that Muckermann's "cinnamic acid hydrazide" with m. p. $101^{\circ}$ (which, as previously mentioned, is formed when ethyl cinnamate is treated with a small excess of hydrazine hydrate in alcohol) is not cinnamic acid hydrazide. In addition to the abnormal reaction with nitrous acid, the following properties are in disagreement with the hydrazide structure:

1) The ultraviolet absorption spectrum does not show the peak at $2800 \AA$, characteristic of the system<smiles>CC(=O)C(C)=C(C)c1ccccc1</smiles>

2) It has not been possible to hydrogenate the compound catalytically with a platinum oxide catalyst to dihydrocinnamic acid hydrazide.

We therefore made an attempt at synthesizing cinnamic acid hydrazide by bringing the mixed anhydride of cinnamic acid and monoethylcarbonic acid (I) to react with hydrazine hydrate *. Hereby a substance is formed in about $65 \%$ yield and m. p. 117-117.5 ${ }^{\circ}$, which is isomeric with Muckermann's compound, the properties of which correspond, however, in every respect to those expected for cinnamic acid hydrazide (II):

1) With nitrous acid cinnamic acid azide (III) is formed.

2) The ultraviolet absorption spectrum (curve 2, Fig. 1) shows a strong absorption maximum at $2750 \AA$.

3) Upon catalytic hydrogenation with a platinum catalyst dihydrocinnamic acid hydrazide (IV) is obtained.

Muckermann's compound must consequently be considered as 3-phenyl-5pyrazelidone (V), a structure which is further evidenced by the fact that we have been able to oxidize the substance to 3-phenyl-5-pyrazolone (VI).

The fact that the substance condenses with aldehydes and ketones seems inconsistent with the pyrazolidone formula, and this is presumably the reason why Muckermann assumed the substance to be cinnamic acid hydrazide.

This property can be explained, however, if betain structures are assigned to the condensation products. The benzylidene compound, for example, can be described by formula VII.

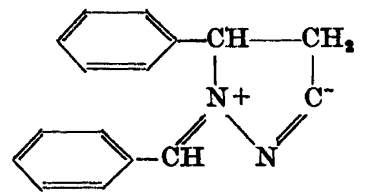

VII

In accordance with this formulation, the absorption spectrum (curve 3, Fig. 1) shows two peaks at $3300 \AA$ and $3470 \AA$, respectively, and moreover the substance is readily hydrolyzed in acid solution. In this connection, it is worth mentioning Pugh's 14 recent observation that condensation of acetone with 3,5,5-trimethyl- $\Delta^{2}$-pyrazoline in the presence of acids leads to the formation of 3,5,5-trimethyl-1-isopropylidenepyrazolinium salts.

* The application of ethyl chlorocarbonate to this problem suggested itself in view of the recent use of this compound in peptide syntheses ${ }^{11-13}$.

Acta Chem. Scand. 9 (1955) No. 9 


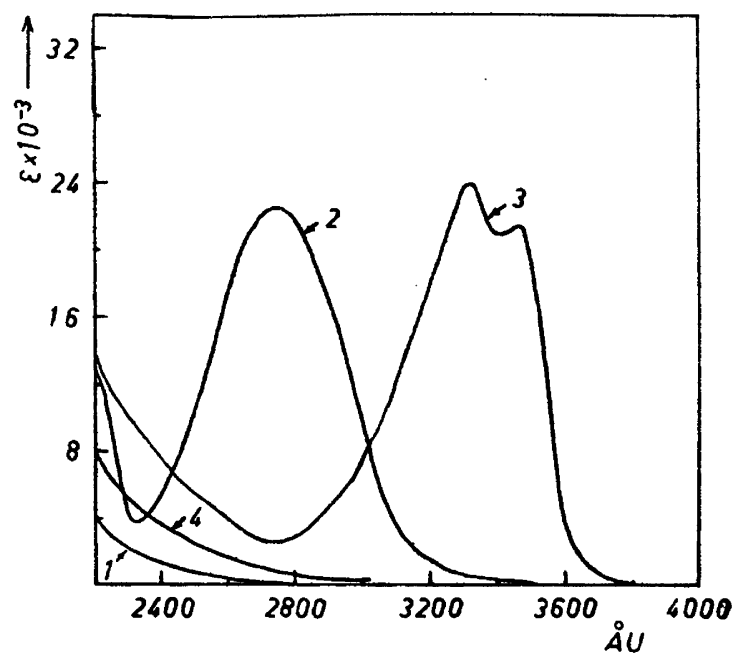

Fig. 1. Ultraviolet absorption spectra.

Curve 1. 3-Phenyl-5-pyrazolidone.

Curve 2. Cinnamic acid hydrazide.

Curve 3. Benzylidene compound of 3-phenyl-5-pyrazolidone.

Curve 4. 2-Benzyl-3-phenyl-5-pyrazolidone.

$\varepsilon=$ molar extinction coefficient (conc. in moles/l.)

Upon catalytical hydrogenation of the benzylidene compound in the presence of a platinum oxide catalyst one mole equivalent of hydrogen is absorbed.

The reaction product which melts at $114.5-115^{\circ}$ has amphoteric properties and must be considered to be 2-benzyl-3-phenyl-5-pyrazolidone (VIII).

In agreement with this formula, the absorption spectrum (curve 4, Fig. 1) shows no peak at $2800 \AA$.

When a palladium catalyst was substituted for platinum in the hydrogenation, the reduction proceeded further under ring opening; when the hydrogenation was stopped as soon as two mole equivalents of hydrogen had been absorbed, dihydrocinnamic acid benzylhydrazide (IX) was obtained. The latter compound was also obtained by hydrogenation of benzylidene cinnamic acid hydrazide $(X)$ over platinum.

Continued hydrogenation of VII over palladium on charcoal causes the uptake of three mole equivalents of hydrogen because the dihydrocinnamic acid benzylhydrazide (IX) is debenzylated and dihydrocinnamic acid hydrazide (IV) is formed.

When refluxing ethyl cinnamate in ethanol with approximately three mole equivalents of hydrazine hydrate, 3-phenyl-5-pyrazolidone is not obtained; the crystalline product (m. p. $\left.103-105^{\circ}\right)$ turned out to be $\beta$-hydrazinodihydrocinnamic acid hydrazide (XI).

With two equivalents of benzaldehyde this substance forms the dibenzylidene compound (XII). 


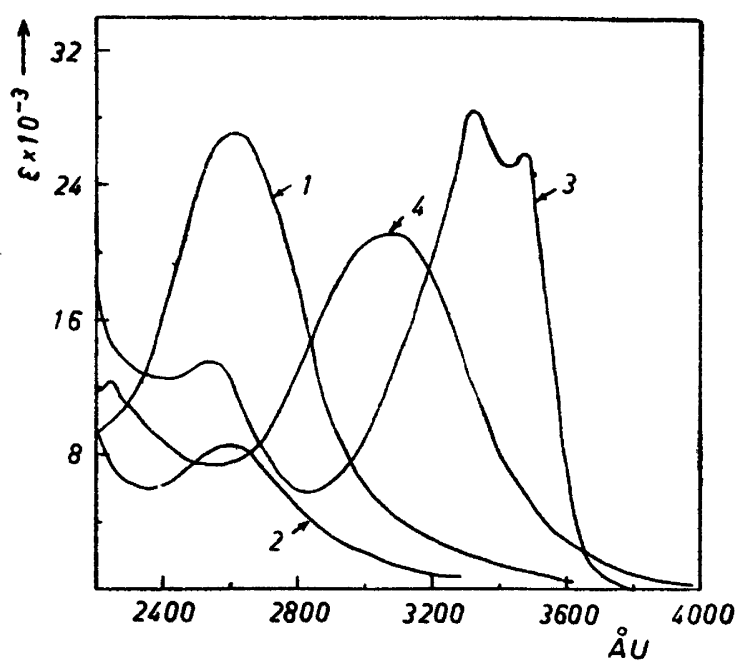

Fig. 2. Ultraviolet absorption spectra.

Curve 1. m-Nitrocinnamic acid hydrazide.

Curve 2. 3-(m-Nitrophenyl)-5-pyrazolidone.

Curve 3. Benzylidene compound of 3-(m-Nitrophenyl)-5-pyrazolidone.

Curve 4. p-Nitrocinnamic acid hydrazide. $\varepsilon=$ molar extinction coefficient (conc. in moles/l.)

During distillation at reduced pressure $\beta$-hydrazinodihydrocinnamic acid hydrazide (XI) splits off hydrazine and forms 3-phenyl-5-pyrazolidone (V), and by catalytical hydrogenation over $\mathrm{Pd}$ on charcoal dihydrocinnamic acid hydrazide (IV) is formed.

As we were unable to convert cinnamic acid hydrazide into 3-phenyl-5pyrazolidone, it is assumed that the first step in the formation of the latter compound is an addition of hydrazine to the double bond in ethyl cinnamate followed by cyclization of the ethyl $\beta$-hydrazinodihydrocinnamate formed during this reaction.

The cyclization, however, is a relatively slow process, and in the presence of an excess of hydrazine the latter reacts with the hydrazinoester forming $\beta$-hydrazinodihydrocinnamic acid hydrazide. As recently shown by Phillips and Mentha ${ }^{15}$, the reaction of methyl cinnamate with guanidine takes place in a similar way.

From the results stated above it might be concluded that Curtius' "mnitrocinnamic acid hydrazide" (m. p. $139^{\circ}$ ) which, upon treatment with nitrous acid, yields 2-nitroso-3-m-nitrophenyl-5-pyrazolidone (XV) is 3-m-nitrophenyl5-pyrazolidone (XIV) and that the substance (m. p. $199^{\circ}$ ) which normally forms $m$-nitrocinnamoyl azide (XVII) actually is $m$-nitrocinnamic acid hydrazide (XVI).

This assumption has been confirmed, since the ultraviolet absorption spectrum of the compound which melts at $199^{\circ}$ shows a strong absorption maxi- 


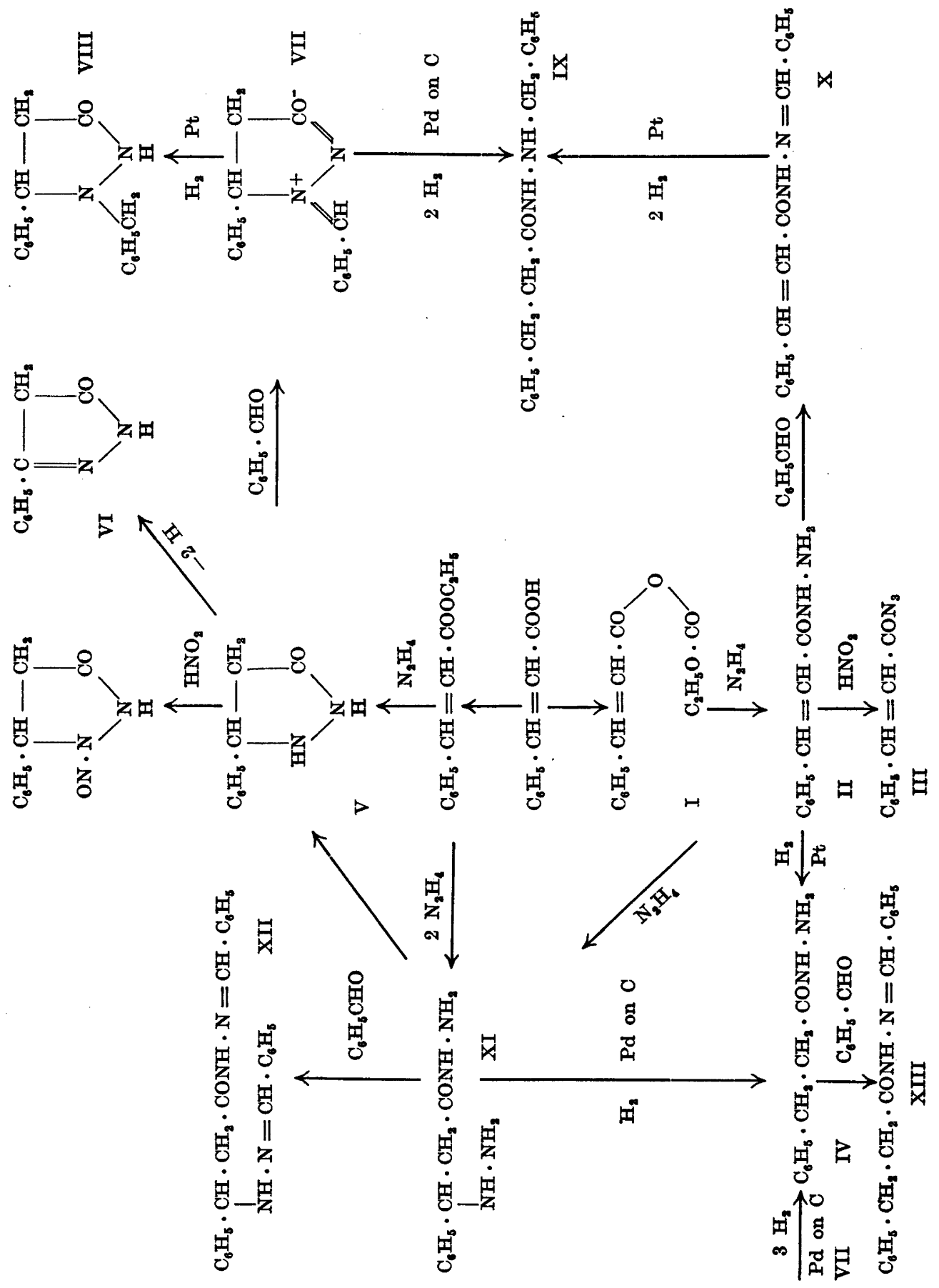

Acta Chem. Scand. 9 (1955) No. 9 

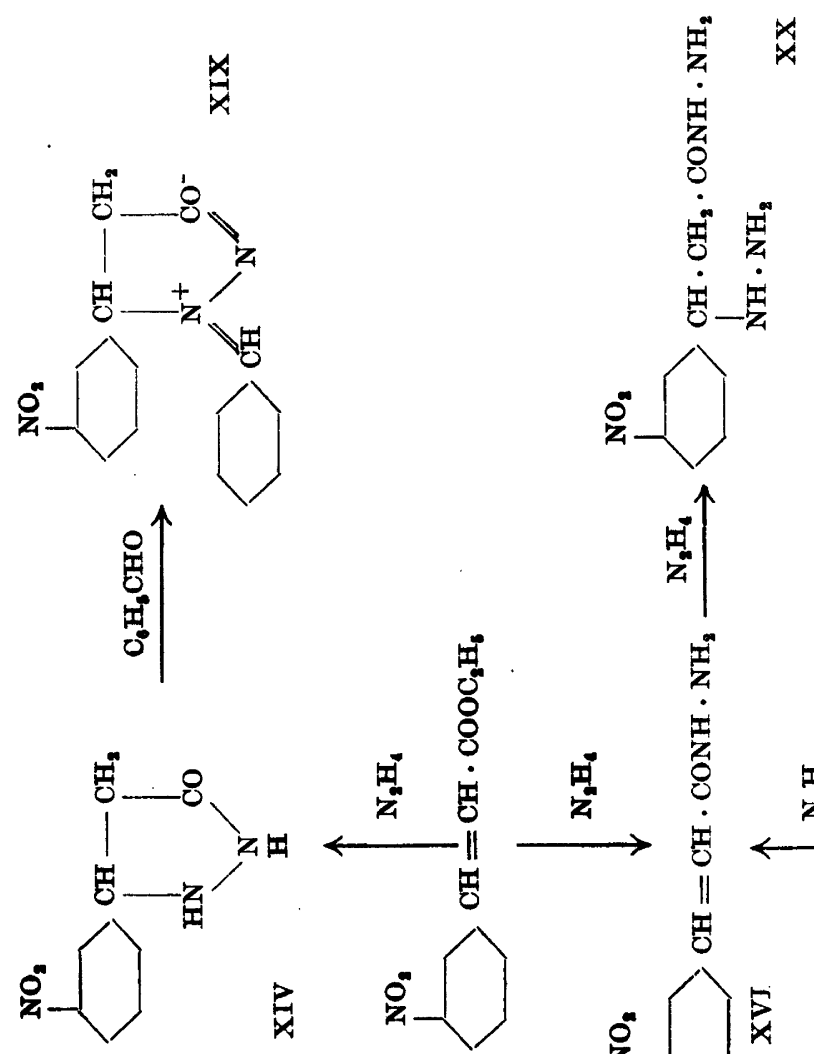

更

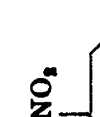

空

范<smiles>O=[SH]OOO</smiles>
官<smiles>CC(=O)OBO[C@H](C)C(=O)O</smiles><smiles>O=CC1CCCS(=O)C1</smiles>

Acta Chem. Scand. 9 (195.5) No. 9 
mum at the same wavelength (2600 $\AA$ ) as does $m$-nitrocinnamic acid, while the compound with m. p. $139^{\circ}$ only absorbs weakly in this region (curve 1 and 2, Fig. 2).

Furthermore, it has been possible to synthesize the compound with $\mathrm{m} . \mathrm{p}$. $199^{\circ}$ by causing the mixed anhydride of $m$-nitrocinnamic acid and monoethylcarbonic acid (XVII) to react with hydrazine hydrate.

In analogy to the benzylidene compound of 3-phenyl-5-pyrazolidone, the structure XIX must be assigned to the benzylidene compound of XIV, and the ultraviolet absorption spectrum is in accordance herewith (curve 3, Fig. 2).

Upon treatment of $m$-nitrocinnamic acid hydrazide (XVI) with hydrazine hydrate, $\beta$-hydrazino- $m$-nitrodihydrocinnamic acid hydrazide (XX) is obtained, although in poor yield only.

Gansser and Rumpf ${ }^{4}$ gave no evidence of the hydrazide structure of the substance they considered to be $p$-nitrocinnamic acid hydrazide. It would therefore be of interest to establish whether this substance actually is $p$-nitrocinnamic acid hydrazide or 3-p-nitrophenyl-5-pyrazolidone.

To that end, we have synthesized $p$-nitrocinnamic acid hydrazide in a manner analogous to the preparation of cinnamic acid hydrazide. The melting point of the product thus obtained was not depressed by admixture with Gansser and Rumpf's compound.

The hydrazide structure of the substance is further evidenced by the ultraviolet absorption spectrum (curve 4, Fig. 2) and by the fact that treatment with nitrous acid leads to the formation of $p$-nitrocinnamoyl azide.

\section{EXPERIMENTAL}

All melting points are corrected.

Cinnamic acid hydrazide (II)

To a stirred, ice-cooled suspension of $5.58 \mathrm{~g}(0.03 \mathrm{~mole})$ of potassium cinnamate in $250 \mathrm{ml}$ of methylene chloride were added $3.25 \mathrm{~g}(0.03 \mathrm{~mole})$ of ethylchlorocarbonate and $6 \mathrm{ml}$ of a $1 \%$ solution of pyridine in methylene chloride. Stirring was continued for two hours at $0-5^{\circ} \mathrm{C}$ and the reaction mixture was then slowly poured into a stirred suspension of $1.5 \mathrm{ml}(0.03 \mathrm{~mole})$ of $100 \%$ hydrazine hydrate in $50 \mathrm{ml}$ of methylene chloride. After filtration, the filtrate was kept in an ice box overnight, then washed with a saturated sodium bicarbonate solution, and dried. The solvent was removed and the residue recrystallized from benzene. Yield: $3.2 \mathrm{~g} \sim 66 \%$; m. p. 117-117.5 $\mathrm{C}$. (Found: $\mathrm{C} \mathrm{66.59}$; $\mathrm{H}$ 6.44; $\mathrm{N}$ 17.10. Calc. for $\mathrm{C}_{2} \mathrm{H}_{10} \mathrm{~N}_{2} \mathrm{O}$ : $\left.\mathrm{C} 66.65 ; \mathrm{H} 6.22 ; \mathrm{N} 17.28\right)$.

\section{Cinnamoyl azide (III)}

$1.62 \mathrm{~g}(0.01 \mathrm{~mole})$ of cinnamic acid hydrazide (II) were dissolved in $20 \mathrm{ml}$ of $4 \mathrm{~N}$ hydrochloric acid. The solution was cooled to $+5^{\circ}$ and an equimolar amount $(690 \mathrm{mg})$ of sodium nitrite in $5 \mathrm{ml}$ of water was added slowly to the stirred liquid. The white precipitate formed was removed by filtration, washed with water, and dried over phosphorus pentoxide in vacuo. Yield: $1.10 \mathrm{~g} \sim 64 \%$; m. p. $82^{\circ}$ (decomp.).

After two recrystallizations from light petroleum $\left(60-90^{\circ}\right)$ the melting point was $85-86^{\circ}$ (decomp.). (Found: C 62.61; H 4.19; N 24.35. Calc. for $\mathrm{C}_{9} \mathrm{H}_{7} \mathrm{~N}_{3} \mathrm{O}$ : C 62.41; H 4.07; N 24.27).

Forster ${ }^{18}$, who has prepared the compound from cinnamoyl chloride and sodium azide reports $\mathrm{m} . \mathrm{p.} 86^{\circ}$ (decom p.).

Acta Chem. Scand. 9 (1955) No. 9 


\section{Dihydrocinnamic acid hydrazide (IV)}

8) From cinnamic acid hydrazide (II). A suspension of $1.62 \mathrm{~g}(0.01 \mathrm{~mole})$ of cinnamic acid hydrazide (II) in $50 \mathrm{ml}$ of absolute ethanol was shaken in the presence of $135 \mathrm{mg}$ of a platinum oxide catalyst * at room temperature under one atmosphere of hydrogen. The theoretical amount of hydrogen was consumed in one hour.

The solution was filtered and concentrated in vacuo. Filtration gave $1.10 \mathrm{~g} \sim 66 \%$ of white crystals which melted at $99.5-100.5^{\circ} \mathrm{C}$. After recrystallization from benzene, m. p. $101-102^{\circ} \mathrm{C}$. (Jordan ${ }^{17}$ reports $\mathrm{m}$. p. $103^{\circ} \mathrm{C}$ ). (Found: C 65.81; H 7.22; N 17.26. Calc. for $\mathrm{C}_{0} \mathrm{H}_{18} \mathrm{~N}_{2} \mathrm{O}$ : $\mathrm{C}$ 65.85; $\mathrm{H} 7.37 ; \mathrm{N} 17.07$ ).

For characterization, we have prepared the benzylidene compound (XIII) as described by Jorden ${ }^{17}$ and found m. p. $133-134^{\circ} \mathrm{C}$ (Jordan reports $132.5^{\circ}$ ).

b) From $\beta$-hydrazinodihydrocinnamic acid hydrazide (XI). $1.94 \mathrm{~g}(0.01 \mathrm{~mole})$ of $\beta$-hydrazinodihydrocinnamic acid hydrazide were suspended in $100 \mathrm{ml}$ of absolute ethanol and catalytically reduced at $70^{\circ}$ under one atmosphere of hydrogen in the presence of $2.5 \mathrm{~g}$ of $10 \%$ palladium-on-charcoal *.

When the theoretical amount of hydrogen had been absorbed, the catalyst was removed and the solution evaporated to dryness under reduced pressure. The residue was recrystallized from benzene. Yield $0.89 \mathrm{~g} \sim 55 \%$ m. p. $99-100.5^{\circ} \mathrm{C}$. The melting point was not depressed by admixture with authentic dihydrocinnamic acid hydrazide.

c. From the benzylidene compound of 3-phenyl-5-pyrazolidone (VII). A solution of $2.50 \mathrm{~g}(0.01 \mathrm{~mole})$ of the benzylidene compound of 3-phenyl-5-pyrazolidone in $100 \mathrm{ml}$ of absolute ethanol was hydrogenated at room temperature under one atmosphere of hydrogen in the presence of $1.25 \mathrm{~g}$ of $10 \%$ palladium-on-charcoal. When three mole equivalents of hydrogen had been absorbed, the catalyst was removed and the solution evaporated to dryness under reduced pressure. The residue was recrystallized from benzene. Yield $1.05 \mathrm{~g} \sim 64 \%$; m. p. $101-102^{\circ}$ alone and by admixture with authentic dihydrocinnamic acid hydrazide.

\section{3 - Phen y l-5 - p y r a olidone (V)}

This compound was prepared as described by Muckermann ${ }^{1}$ for cinnamic acid hydrazide. The yield and the melting point were in agreement with the values reported by Muckermann. The molecular weight was determined to be 168 (Rast); calc. 162.

\section{3 - Phen y l - 5 - p y r a olone (VI)}

To a stirred ice-cooled solution of $3.24 \mathrm{~g}(0.02 \mathrm{~mole})$ of 3-phenyl-5-pyrazolidone (V) in $40 \mathrm{ml}$ of pyridine was added in the course of 15 minutes a solution of $6.4 \mathrm{~g}(0.04 \mathrm{~mole})$ of CuSO, in $40 \mathrm{ml}$ of water. After addition of $100 \mathrm{ml}$ of water the precipitate which formed was filtered off, washed with water, and triturated with $15 \mathrm{ml}$ of conc. hydrochloric acid. The 3-phenyl-5-pyrazolone hydrochloride which formed was filtered, washed with conc. hydrochloric acid, and dried.

The free 3-phenyl-5-pyrazolone was liberated by triturating the hydrochloride with a saturated sodium bicarbonate solution. Filtration and washing with water yielded 1.65 $\mathrm{g} \sim 51 \%$ of air-dried product which melted at $236-244^{\circ} \mathrm{C}$. After recrystallization from ethanol the melting point was $243-244^{\circ}$, and this was not depressed by admixture with authentic 3-phenyl-5-pyrazolone. The I.R.-spectra of the two products were identicel tood

$\begin{array}{ll}\text { The benzylidene compound of } & \text { 3-phenyl-5-pyra- } \\ \text { zolidone (VII) } & \end{array}$

This compound was prepared as described by Muckermann" for "benzylidene cinnamic acid hydrazide".

* Obtained from Baker Platinum Ltd., 52 High Holborn, London, W.C. 1. 
We have found it more convenient to recrystallize the compound from benzene instead of $50 \%$ ethanol and have by this procedure obtained another modification, which melts at $200-201^{\circ} \mathrm{C}$. Mol.wt. 264 (Rast); calc. 250.

\section{2- B enz y. - 3-phen y l-5 - p yrazolidone (VIII)}

$1.00 \mathrm{~g}(0.004 \mathrm{~mole})$ of the benzylidene compound of 3-phenyl-5-pyrazolidone (VII) was dissolved in $50 \mathrm{ml}$ of absolute ethanol and catalytically reduced at room temperature under one a.tmosphere of hydrogen in the presence of $50 \mathrm{mg}$ of a platinum oxide catalyst. When the theoretical amount of hydrogen had been absorbed (thirty minutes), the catalyst was removed and the solution evaporated to dryness under reduced pressure. The residue (m. p. 113.5-114 ${ }^{\circ} \mathrm{C}$ ) was recrystallized from $50 \%$ ethanol. Yield $620 \mathrm{mg}$ $\sim 62 \%$; m. p. $114.5-115^{\circ} \mathrm{C}$. (Found: $\mathrm{C} 75.94 ; \mathrm{H}$ 6.35; $\mathrm{N}$ 11.20. Calc. for $\mathrm{C}_{16} \mathrm{H}_{10} \mathrm{~N}_{2} \mathrm{O}$ : C 76.17; H 6.39; N 11.11).

\section{Dihydrocinnamic acid benzylhydrazide hydrochloride (IX)}

a) From the benzylidene compound of 3-phenyl-5-pyrazolidone (VII). A solution of $2.50 \mathrm{~g}$ ( $0.01 \mathrm{~mole})$ of the benzylidene compound of 3-phenyl-5-pyrazolidone (VII) in 150 $\mathrm{ml}$ of absolute ethanol was shaken in the presence of $1.25 \mathrm{~g}$ of $10 \%$ palladium-oncharcoal at room temperature under one atmosphere of hydrogen. When two mole equivalents of hydrogen had been absorbed, the catalyst was removed and the solution evaporated to dryness under reduced pressure. The oily residue was dissolved in absolute ethanol and converted into the hydrochloride by addition of ethanolic hydrogen chloride followed by ether. Yield $1.50 \mathrm{~g} \sim 52 \% ; \mathrm{m}$. p. $163-170^{\circ} \mathrm{C}$. After recrystallization from absolute ethanol the melting point was $169-171^{\circ} \mathrm{C}$. (Found: $\mathrm{C}$ 65.83; H 6.64; $\mathrm{N}$ 9.71; $\mathrm{Cl}$ 12.63. Calc. for $\mathrm{C}_{16} \mathrm{H}_{29} \mathrm{ClN}_{2} \mathrm{O}$ : $\left.\mathrm{C} 66.09 ; \mathrm{H} 6.59 ; \mathrm{N} 9.64 ; \mathrm{Cl} 12.19\right)$.

b) From benzylidene cinnamic acid hydrazide $(X) .2 .50 \mathrm{~g}(0.01 \mathrm{~mole})$ of benzylidene cinnamic acid hydrazide were suspended in $50 \mathrm{ml}$ of dioxan and catalytically reduced at $70^{\circ}$ under one atmosphere of hydrogen in the presence of $125 \mathrm{mg}$ of a platinum oxide catalyst. When two mole equivalents of hydrogen had been absorbed in the course of four hours, the catalyst was removed and the solvent evaporated at reduced pressure. The oily residue was worked up as described under a). Yield $1.50 \mathrm{~g} \sim 52 \%$; m. p. $173-$ $75^{\circ} \mathrm{C}$. (Found: $\mathrm{C} \mathrm{66.13} ; \mathrm{H} 7.08 ; \mathrm{N} 9.51 ; \mathrm{Cl} 12.24$. Calc. for $\mathrm{C}_{16} \mathrm{H}_{19} \mathrm{ClN}_{2} \mathrm{O}: \mathrm{C} 66.09 ; \mathrm{H} 6.59$; N 9.64; $\mathrm{Cl} \mathrm{12.19).}$

The I.R.-spectra of the two products were identical.

\section{Benzylidene cinnamic acid hydrazide}

To a stirred solution of $1.62 \mathrm{~g}(0.01$ mole) of cinnamic acid hydrazide in $25 \mathrm{ml}$ of ethanol were added $25 \mathrm{ml}$ of water, $1 \mathrm{ml}$ of benzaldehyde and two drops of $4 \mathrm{~N}$ sulfuric acid. After 30 minutes the white precipitate formed was filtered off, washed with ethanol, and dried. Yield $2.1 \mathrm{~g} \sim 84 \%$; m. p. $225.5-227.5^{\circ} \mathrm{C}$. Recrystallization from ethanol yielded $1.8 \mathrm{~g}$ which melted at $229-230^{\circ} \mathrm{C}$. (Found: C 76.70; H 5.63; $\mathrm{N} 11.35$. Calc. for $\mathrm{C}_{16} \mathrm{H}_{14} \mathrm{~N}_{2} \mathrm{O}$ : $\mathrm{C}$ 76.79; $\mathrm{H}$ 5.64; 11.19).

\section{$\beta$ - Hydrazinodihydrocinnamic acid hydrazidel}

a) From ethyl cinnamate. A mixture of $17.6 \mathrm{~g}(0.1 \mathrm{~mole})$ of ethyl cinnamate, $18 \mathrm{ml}$ $(0.36 \mathrm{~mole})$ of $100 \%$ hydrazine hydrate and $10 \mathrm{ml}$ of ethanol was refluxed for eight hours. The solvent was removed in vacuo and the residue was kept in a vacuum desiccator over phosphorus pentoxide for three days. The resulting mass was triturated with $15 \mathrm{ml}$ of methanol, filtered, and recrystallized from methanol-ether. Yield $11.0 \mathrm{~g} \sim 56 \%$; m. p. $103-105^{\circ}$ C. (Found: C 55.69; $\mathrm{H} 7.33 ; \mathrm{N} 28.79$. Calc. for $\mathrm{C}_{2} \mathrm{H}_{16} \mathrm{~N}_{4} \mathrm{O}$ : C 55.67; $\mathrm{H}$ 7.27; N 28.85).

Acta Chem. Scand. 9 (1955) No. 9 
b) From cinnamic acid hydrazide (II). A mixture of $1.62 \mathrm{~g}(0.01 \mathrm{mol \theta})$ cinnamic acid hydrazide (II), $1.5 \mathrm{ml}(0.03 \mathrm{~mole})$ of $100 \%$ hydrazine hydrate and $4 \mathrm{ml}$ of ethanol was refluxed for two hours. The solvent was removed in vacuo and the residual paste was kept in a vacuum desiccator over concentrated sulphurie acid over-night to remove excess hydrazine. The resulting solid mass was recrystellized from methanol-ether. Yield $1.05 \mathrm{~g} \sim 54 \%$; m. p. $101-103^{\circ} \mathrm{C}$. The melting point was not depressed by admixture with the $\beta$-hydrazinodihydrocinnamic acid hydrazide from a) above.

Dibenzylidene- $\beta-$ hydrazinodihydrocinnamic acid h y drazide (XII)

To a stirred solution of $194 \mathrm{mg}(0.001 \mathrm{~mole})$ of $\beta$-hydrazinodihydrocinnamic acid hydrazide in $5 \mathrm{ml}$ of ethanol were added $5 \mathrm{ml}$ of water, $0.3 \mathrm{ml}$ of benzaldehyde and one drop of $4 \mathrm{~N}$ sulphuric acid. After 30 minutes the white precipitate was filtered off, washed with othanol, and dried. Yield $340 \mathrm{mg} \sim 92 \%$; m. p. $180-183^{\circ} \mathrm{C}$. After recrystallization from methyl-cellosolve the melting point was $181-183^{\circ} \mathrm{C}$. (Found: C 74.59; H 6.18; $\mathrm{N}$ 15.13. Calc. for $\mathrm{C}_{28} \mathrm{H}_{22} \mathrm{~N}_{4} \mathrm{O}$ : C 74.57; $\mathrm{H}$ 5.99; $\mathrm{N}$ 15.12).

Conversion of $\beta$-hydrazinodihydrocinnamic acid hydrazide (XI) to 3 -phenyl-5-pyrazolidone (V)

$3.88 \mathrm{~g}(0.02 \mathrm{~mole})$ of $\beta$-hydrazinodihydrocinnamic acid hydrazide were distilled in vacuo. The fraction distilling at $195-200^{\circ} / 1.5 \mathrm{~mm}$ was collected. The distillate solidified to a white crystalline mass and was recrystallized from ethanol. Yield $1.67 \mathrm{~g} \sim 51 \%$; m. p. $101^{\circ}$ alone and by admixture with 3-phenyl-5-pyrazolidone.

$$
m \text { - Nitrocinnamic acid hydrazide (XVI) }
$$

This compound was prepared from the potassium salt of $m$-nitrocinnamic acid in analogy with the preparation of cinnamic acid hydrazide (II). Yield of crude product $65 \%$. One recrystallization from ethanol yielded material melting at $200-201^{\circ} \mathrm{C}$. (Curtius ' reports $198^{\circ}$ ). The melting point was not depressed by admixture with $m$ nitrocinnamic acid hydrazide (m. p. 200-201 $)$ propared as desoribed by Curtius 2 .

3 - (m-Nitrophenyl)-5-pyrazolidone (XIV) and the benzylidene compound of 3-(m-Nitrophenyl)-5-pyrazolidone (XIX)

These compounds were prepared as described by Curtius and Bleicher ${ }^{2}$ for $m$-nitroainnamic acid hydrazide (m. p. $139^{\circ}$ ) and benzylidene $m$-nitrocinnamic acid hydrazide (m. p. $206.5^{\circ}$ ), respectively. The yields and melting points were in agreement with the values reported by these authors.

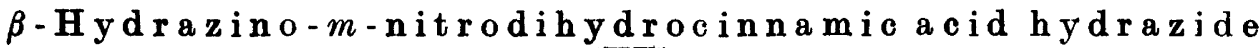
$(\mathrm{XX})$

A mixture of $2.07 \mathrm{~g}(0.01 \mathrm{~mole})$ of $m$-nitrocinnamic acid hydrazide (XVI), $1.5 \mathrm{ml}$ $(0.03 \mathrm{~mole})$ of $100 \%$ hydrazine hydrate and $4 \mathrm{ml}$ of absolute ethanol was refluxed for 30 minutes. The ethenol was removed in vacuo and the residue was kept in a vacuum desiccator over concentrated sulphuric aoid overnight. Crystallization from methanolether yielded $150 \mathrm{mg}$ of a product, melting at $101-103^{\circ}$. (Found: $\mathrm{C} \mathrm{45.04;} \mathrm{H} \mathrm{5.50;}$ $\mathrm{N}$ 29.28. Calc. for $\mathrm{C}_{6} \mathrm{H}_{18} \mathrm{~N}_{6} \mathrm{O}_{2}$ : C 45.19; $\mathrm{H} 5.48 ; \mathrm{N} 29.28$ ).

$$
p \text { - Nitrocinnamic acid hydrazide }
$$

This compound was prepared from the potassium salt of $p$-nitrocinnamic acid in analogy with the preparation of cinnamic acid hydrazide (II). Yield of crude product $70 \%$. After one recrystallization from ethanol the melting point was $215-216^{\circ} \mathrm{C}$

Acta Chem. Scand. 9 (1955) No. 9 
(decomp.) alone and by admixture with $p$-nitrocinnamic acid hydrazide prepared as described by Gansser and Rumpf ^. (Found: C 52.05; $\mathrm{H} 4.47 ; \mathrm{N} 19.80$. Calc. for $\mathrm{C}_{9} \mathrm{H}_{9} \mathrm{~N}_{3} \mathrm{O}_{2}$ : C 52.17; H 4.38; N 20.28).

$$
p^{\prime}-\mathrm{N} \text { itrocinn a mo y lazide }
$$

To a stirred solution of $300 \mathrm{mg}$ of $p$-nitrocinnamic acid hydrazide in $5 \mathrm{ml}$ of glacial acetic acid were added $200 \mathrm{mg}$ of sodium nitrite. After 15 minutes at room temperature the yellow precipitate formed was filtered, washed with water, and recrystallized from chloroform-petrolether. M. p. $119^{\circ} \mathrm{C}$ (decomp.). (Found: C 49.65; H 2.81; N 25.75. Calc. for $\mathrm{C}_{9} \mathrm{H}_{6} \mathrm{~N}_{4} \mathrm{O}_{3}: \mathrm{C} 49.53 ; \mathrm{H} 2.77 ; \mathrm{N} 25.67$ ).

Acknowledgment. The authors wish to acknowledge their gratitude to E. Juhl Nielsen for his helpful suggestions during the course of this work. We are also indebted to J. Buur-Jensen for the ultraviolet and infrared absorption spectra and to G. Cornali for the microanalyses.

\section{REFERENCES}

1. Muckermann, E. J. prakt. Chem. (2) 83 (1911) 513; Ber. 42 (1909) 3449.

2. Curtius, T. and Bleicher, P. A. J. prakt. Chem. (2) 107 (1924) 86.

3. Curtius, T. and Kenngott, E. J. prakt. Chem. (2) 107 (1924) 99.

4. Gansser, Ch. and Rumpf, P. Helv. Chim. Acta 36 (1953) 1423.

5. Lieser, Th. and Kemmner, K. Ber. 84 (1951) 4.

6. Ruggli, P. and Theilheimer, W. Helv. Chim. Acta 24 (1941) 899.

7. Freri, M. Gazz. chim. ital. 66 (1936) 23.

8. Curtius, T. and Radenhausen, R. J. prakt. Chem. (2) 52 (1895) 433.

9. Darapsky, A. J. prakt. Chem. (2) 147 (1936) 145.

10. Stodole, F. H. J. org. Chem. 13 (1948) 757.

11. Boissonnas, R. A. Helv. Chim. Acta 34 (1951) 874.

12. Wieland, T. and Bernhard, H. Ann. 572 (1951) 190.

13. Vaughan, J. R., Jr. J. Am. Chem. Soc. 73 (1951) 3547; 74 (1952) 676.

14. Pugh, W. J. Chem. Soc. 1954 2423, 2429.

15. Phillips, A. P. and Mentha, J. J. Am. Chem. Soc. 76 (1954) 574.

16. Forster, M. O. J. Chem. Soc. 95 (1909) 433.

17. Jordan, H. J. prakt. Chem. (2) 64 (1901) 297.

Received August 9, 1955.

Acta Chem. Scand. 9 (1955) No. 9 